\title{
Natural and synthetic arsenic sulfide pigments in Japanese woodblock prints of the late Edo period
}

\author{
Stephanie Zaleski ${ }^{1,2}$, Yae Takahashi $^{1}$ and Marco Leona ${ }^{1 *}$ (])
}

\begin{abstract}
We recently described the use of an artificial arsenic sulfide pigment in Japanese woodblock prints from the Meiji period (1868-1912): we now expand on our previous work by investigating arsenic sulfide pigments used in Japanese woodblock prints of the late Edo period (1615-1868) and early Meiji period. The series of eight prints A Tour of the Waterfalls in Various Provinces (Shokoku Taki Meguri), by Katsushika Hokusai, issued between 1833 and 1834 is known to have been reproduced from entirely new blocks at some point during the late Edo or early Meiji periods. The two sets, original and copies are characterized by visually distinct color palettes as well as several differences in the image. Two such sets in the collection of the Metropolitan Museum of Art were analyzed with particular attention to the yellow, orange, and green printed areas. X-ray fluorescence spectrometry, Raman microspectroscopy, and scanning electron microscopy-energy dispersive spectroscopy revealed the use of natural orpiment in the original set and of artificial arsenic sulfide pigments in the reproduction set. In addition, the reproduction set features extensive use of ultramarine blue, the synthetic equivalent to lapis lazuli. This pigment, available commercially in Europe from 1830 onward has been documented in Japanese art so far only in a handful of late Edo period paintings. The results of our comparative analysis further highlight differences in pigment use between Edo and Meiji periods, and point to arsenic sulfide pigments as useful markers for the date of original production for popular prints of the Edo period.
\end{abstract}

Keywords: Japanese woodblock prints, Raman microspectroscopy, Micro-XRF, SEM-EDS, Arsenic sulfides, Orpiment, Ultramarine blue

\section{Introduction}

Arsenic sulfides, ranging from bright yellow to orange in color, have been used as pigments since antiquity $[1$, 2]. The two arsenic sulfides most commonly identified in works of art are orpiment $\left(\mathrm{As}_{2} \mathrm{~S}_{3}\right)$ and realgar $(\alpha-\mathrm{AsS}$ or $\mathrm{As}_{4} \mathrm{~S}_{4}$ ), a yellow and an orange/red pigment, respectively. Orpiment in particular was highly desirable as a pigment because of its bright, warm, yellow color, mimicking that of gold. Despite its striking visual appearance, the micaceous, flaky character of orpiment makes it challenging to grind for use as a pigment. The first reference in Western Europe to orpiment as an artificially produced

\footnotetext{
*Correspondence: marco.leona@metmuseum.org

${ }^{1}$ Department of Scientific Research, The Metropolitan Museum of Art, New York, NY 10028, USA

Full list of author information is available at the end of the article
}

pigment is given by Cennino Cennini, and the production process was first described in fifteenth century manuscripts [3-5]. Artificial orpiment was obtained by the dry process method, whereby natural orpiment was heated and recrystallized by sublimation, with or without the addition of sulfur. Arsenical ore and sulfur could also be used as starting materials. Artificial orpiment could also be synthesized by reacting $\mathrm{H}_{2} \mathrm{~S}$ gas with a hydrochloric acid solution of $\mathrm{As}_{2} \mathrm{O}_{3}$ and collecting the resultant yellow precipitate: this preparation is known as the wet process method $[1,2]$. Dry process artificial orpiment is typically characterized by smaller and more regular particle size compared to the natural mineral, as well as by the presence of colorless $\mathrm{As}_{2} \mathrm{O}_{3}$ particles. The wet process results in round and regular particles of finer size than the dry process, rarely used as a pigment $[1,2]$. Grundmann and 
coworkers suggest classifying artificial orpiment obtained from heating as orpiment glass $\left(\mathrm{g}-\mathrm{As}_{2} \mathrm{~S}_{3}\right)$ and any sublimation products as arsenic sulfide glass $\left(\mathrm{g}-\mathrm{As}_{\mathrm{x}} \mathrm{S}_{\mathrm{x}}\right.$ ) [6]. For ease of discussion, this work will refer to any dry process orpiment as artificial arsenic sulfide, unless when citing historical sources explicitly using the name artificial orpiment.

Visual observation cannot accurately distinguish between natural and artificial arsenic sulfides. Polarized light microscopy (PLM), X-ray diffraction (XRD) and Raman microspectroscopy have been used to differentiate various classes of dry process artificial arsenic sulfides $[2,6,7]$. Recent work by Vermeulen et al. used PLM, Raman and scanning electron microscopy with energy dispersive spectrometry (SEM-EDS) to identify an artificial arsenic sulfide pigment in nineteenth century painted decorative panels in the Japanese tower in Laeken, Belgium [8]. The minimally invasive nature and high chemical sensitivity of analytical techniques such as XRF, Raman, and SEM-EDS makes them highly suitable as well for characterization of arsenic sulfide pigments in woodblock prints.

Large mineral deposits of orpiment and realgar can be found in Asia (particularly in Southeastern China), making natural arsenic sulfides a common painting material in Chinese art starting in the fifth and sixth centuries [1, 9-12]. Despite the longstanding use of orpiment in Chinese painting, orpiment does not appear in Japanese paintings before the mid-seventeenth century, becoming more common by the nineteenth century $[13,14]$. Previously published studies discuss a shift in the usage of natural to artificial arsenic sulfides as a yellow pigment during the late Edo period, but do not define an exact time period of this shift $[15,16]$. Recent work from Luo et al. demonstrates the exclusive use of artificial arsenic sulfide as a yellow pigment for Japanese woodblock prints dated between 1864 and 1895 [17]. The authors cite the earliest known reference to artificial arsenic sulfide production in Japan, dating to 1846, where Takamatsu describes heating arsenical ore with sulfur to produce a yellow pigment [18]. Prior to 1846, the source and production of artificial arsenic sulfide pigments and their use in Japanese woodblock prints has not been well studied.

In this study, we expand upon the work of Luo et al. by characterizing arsenic sulfide pigments used in Japanese woodblock prints dated to $1833-1834$. The prints studied herein are from a thematic series designed by Katsushika Hokusai titled A Tour of the Waterfalls in Various Provinces (Shokoku Taki Meguri). Hokusai's landscapes from the Tempyō period (1830-1844) are revered for their unique rendering of natural scenes and dominant blue tones. The onset of the "blue revolution" during this time, primarily due to the introduction of Prussian blue in Japan, saw a shift in the color palette used, from soft tones to striking blues, greens and yellows. The collection of Japanese woodblock prints at The Metropolitan Museum of Art consists of approximately 255 works by Hokusai and his followers $[19,20]$. Among them are two complete sets of the of the eight-print Waterfalls series (sixteen prints in total). Several examples from each set were published by Keyes and Morse in a study describing how the original print series was copied in the late Edo period or early Meiji period from entirely redrawn blocks [21]. The two sets are distinguished by slightly different color palettes and by several minor variations in drawing. In keeping with Keyes and Morse's notation we will henceforth refer to the original set as Set A and the reproduction as Set B.

A multi-technique analytical approach, including XRF, Raman, and SEM-EDS analysis, was used to characterize the arsenic sulfide pigments used in the prints. Our study showed that natural orpiment was used in Set A and the artificial pigment (with one notable occurrence of natural orpiment) in Set B. Additionally, a characteristic distribution for the co-occurrence of specific blue pigments with natural orpiment or the artificial arsenic sulfide to obtain a green color was seen for each print set. Prints in Set A consistently feature Prussian blue and indigo mixed with natural orpiment whereas in prints from Set B artificial arsenic sulfide is mixed with Prussian blue, indigo, and ultramarine blue for the green. Our experimental results, along with historic documentation describing the production and sources of arsenic pigments, provide further understanding of arsenic sulfide pigments use in Japanese woodblock printing during the late Edo period.

\section{Experimental \\ Samples}

In total, 16 prints from the series: A Tour of the Waterfalls in Various Provinces (Shokoku Taki Meguri), dated 1833-1835, were investigated in this study. Table 1 lists the Accession Number and title of each print. XRF and Raman analysis were performed non destructively on the prints. Microscopic samples were removed for SEMEDS analysis.

\section{XRF}

XRF measurements were performed using a Bruker ARTAX 400 micro-XRF spectrometer, using unfiltered $\mathrm{Rh}$ radiation at $50 \mathrm{kV}$ and $700 \mu \mathrm{A}$, with a $1 \mathrm{~mm}$ collimator. Spectra were acquired for $120 \mathrm{~s}$ live-time accumulations.

\section{Raman microspectroscopy}

Raman measurements were performed using a Bruker Senterra Raman spectrometer coupled with an 
Table 1 Summary of prints analyzed in this work from A Tour the Waterfalls in Various Provinces (Shokoku Taki Meguri) series by Katsushika Hokusai in The Metropolitan Museum of Art collection

\begin{tabular}{|c|c|c|}
\hline & MMA Acc. No. & Title \\
\hline \multirow[t]{8}{*}{ Set $A$} & JP2924 & $\begin{array}{l}\text { Kirifuri Waterfall at Kurokami Mountain in Shimo- } \\
\text { tsuke (Shimotsuke Kurokamiyama Kirifuri no taki) }\end{array}$ \\
\hline & JP2925 & $\begin{array}{l}\text { Ono Waterfall on the Kisokaidō (KisokaidōOno } \\
\text { no bakufu) }\end{array}$ \\
\hline & JP2926 & $\begin{array}{l}\text { Kiyotaki Kannon Waterfall at Sakanoshita on the } \\
\text { Tōkaidō (Tōkaidō Sakanoshita Kiyotaki kannon) }\end{array}$ \\
\hline & JP2927 & $\begin{array}{l}\text { The Waterfall Where Yoshitsune Washed his } \\
\text { horse at Yoshino in Yamato Province (Washü } \\
\text { Yoshino Yoshitsune uma arai no taki) }\end{array}$ \\
\hline & JP2928 & $\begin{array}{l}\text { The Amida falls in the far reaches of the } \\
\text { Kisokaidō Road (Kisoji no oku Amida-ga-taki) }\end{array}$ \\
\hline & JP2929 & $\begin{array}{l}\text { The Falls at Aoigaoka in the Eastern Capital (Tōto } \\
\text { Aoigaoka no taki) }\end{array}$ \\
\hline & JP2930 & $\begin{array}{l}\text { Rōben Waterfall at Ōyama in Sagami Province } \\
\text { (Sōshū } \bar{O} \text { yama Rōben no taki) }\end{array}$ \\
\hline & JP2931 & $\begin{array}{l}\text { Yōrō Waterfall in Mino Province (Mino no Yōrō } \\
\text { no taki) }\end{array}$ \\
\hline \multirow[t]{8}{*}{ Set B } & JP1081 & $\begin{array}{l}\text { Kirifuri Waterfall at Kurokami Mountain in Shimo- } \\
\text { tsuke (Shimotsuke Kurokamiyama Kirifuri no taki) }\end{array}$ \\
\hline & JP1082 & $\begin{array}{l}\text { Ono Waterfall on the Kisokaidō (Kisokaidō Ono } \\
\text { no bakufu) }\end{array}$ \\
\hline & JP1083 & $\begin{array}{l}\text { Kiyotaki Kannon Waterfall at Sakanoshita on the } \\
\text { Tōkaidō (Tökaidō Sakanoshita Kiyotaki kannon) }\end{array}$ \\
\hline & JP1084 & $\begin{array}{l}\text { The Waterfall Where Yoshitsune Washed His } \\
\text { Horse at Yoshino in Yamato Province (Washü } \\
\text { Yoshino Yoshitsune uma arai no taki) }\end{array}$ \\
\hline & $J P 1085$ & $\begin{array}{l}\text { The Amida Falls in the far reaches of the } \\
\text { Kisokaidō Road (Kisoji no oku Amida-ga-taki) }\end{array}$ \\
\hline & JP1086 & Fall of Aoiga Oka, Yedo (Tōto Aoigaoka no taki) \\
\hline & JP1087 & $\begin{array}{l}\text { Rōben Waterfall at Ōyama in Sagami Province } \\
\text { (Sōshū Ōyama Rōben no taki) }\end{array}$ \\
\hline & JP1088 & $\begin{array}{l}\text { Yōrō Waterfall in Mino Province (Mino no Yōrō } \\
\text { no taki) }\end{array}$ \\
\hline
\end{tabular}

LMPlanFL Olympus $50 \times$ long working distance microscope objective and a charge-coupled device (CCD) detector. A continuous wave diode laser, emitting light at $785 \mathrm{~nm}$, was used as the excitation source, and a 1200 rulings $/ \mathrm{mm}$ holographic grating provided a spectral resolution of $3-5 \mathrm{~cm}^{-1}$. All Raman spectra presented in this work were recorded with $785 \mathrm{~nm}$ laser excitation, $1 \mathrm{~mW}$ output laser power at the sample and an acquisition time of $15 \mathrm{~s}$, unless otherwise noted. Spectra were acquired using OPUS 7.0 Raman software and processed with OriginLab 9.0.

\section{SEM-EDS}

Prior to SEM analysis, single paper fibers or single particle grains were mounted on an aluminum stub using an ultra-smooth adhesive carbon tab and coated with a
$10 \mathrm{~nm}$ carbon layer. SEM analysis was performed using a FE-SEM Zeiss Eigma HD, equipped with an Oxford Instrument X-MaxN 80 SDD detector. Back scattered (BSE) and/or secondary electron (SE) images and EDS analyses were performed at an accelerating voltage of $20 \mathrm{kV}$ and at a working distance of $8.5 \mathrm{~mm}$ under high vacuum conditions. EDS data was acquired and processed using AZtec software system, v 2.2 SP2 (Oxford Instruments).

\section{Results}

Hokusai's A Tour of the Waterfalls in Various Provinces (Shokoku Taki Meguri) is a thematic set of eight total designs depicting famous waterfalls in Japan. Two sets of the prints are included in collection of The Metropolitan Museum of Art collection: we studied all 16 impressions (Table 1). Upon visual inspection, the tones of the yellows and greens used in each print pair appeared different, where one set of prints used tones of bright yellow and green and the other dull yellow and blue-green tones (Fig. 1). For ease of discussion, and for consistency with Keyes and Morse [21], we have grouped the prints as Set A (bright yellow tones) and Set B (dull yellow tones), as listed in Table 1. We applied a multi-technique approach to analyze the yellow, green, and blue pigments used in each print. Non-invasive analysis by XRF indicated the presence of arsenic and sulfur in all yellow and green areas of the prints. Iron was also detected in all blue and green areas, suggestive of the use of Prussian blue.

Raman analysis of single yellow pigment particles from the prints revealed the use of two different arsenic sulfide pigments. Raman spectra acquired from the yellow pigments in the prints belonging to Set A displayed sharp, distinct peaks at $66,105,136,154,179,202,291,310,354$, and $381 \mathrm{~cm}^{-1}$ (Fig. 2), which agreed well with reference Raman spectra of natural orpiment [22, 23]. In contrast, Raman spectra acquired from prints in Set B generally displayed peaks at 193, 232, 471, 493 and a broad peak centered at $330-340 \mathrm{~cm}^{-1}$ (Fig. 2). The peaks at 193, 232, 330-340 and $493 \mathrm{~cm}^{-1}$ are assigned to various As-S vibrational modes and specifically, the broad peak centered at $340 \mathrm{~cm}^{-1}$ strongly indicates an amorphous arsenic sulfide, or artificial orpiment $\left(\mathrm{g}-\mathrm{As}_{2} \mathrm{~S}_{3}\right.$ or $\left.g-\mathrm{As}_{\mathrm{x}} \mathrm{S}_{\mathrm{x}}\right)$ [24-28]. The peak centered at $471 \mathrm{~cm}^{-1}$ is characteristic of free sulfur. The artificial orpiment spectra agreed well with previously published work $[8,17]$.

SEM-EDS analysis was performed to investigate the arsenic sulfide pigment particle size and morphology and to determine the relative amounts of arsenic and sulfur present. Paper fibers from yellow regions were sampled to be investigated with SEM-EDS analysis. SEM images of a sample acquired from JP2925 (Set A) show platelet-like arsenic-containing particles, ranging from 

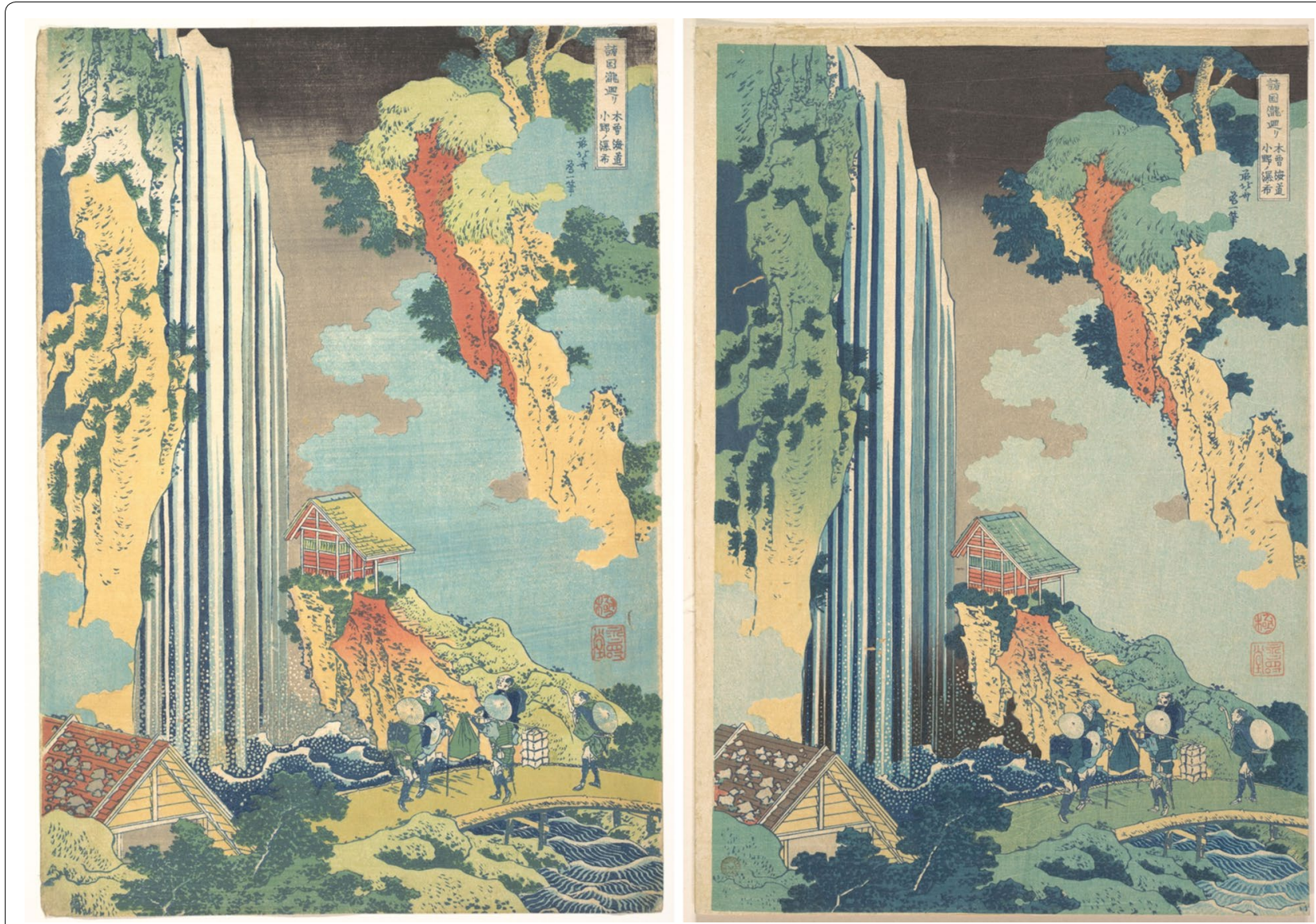

Fig. 1 Left: Ono Waterfall on the Kisokaidō (Kisokaidō Ono no bakufu), from the series A Tour of Waterfalls in Various Provinces (Shokoku taki meguri) by Katsushika Hokusai. The Metropolitan Museum of Art, 14 3/4 × 10 1/4 in., Accession Number JP2925. Henry L. Phillips Collection, Bequest of Henry L. Phillips, 1939. This print is part of Set A. (right) Ono Waterfall on the Kisokaidō (Kisokaidō Ono no bakufu), from the series A Tour of Waterfalls in various provinces (Shokoku taki meguri) by Katsushika Hokusai. The Metropolitan Museum of Art, 14 7/8 × 10 5/16 in., Accession Number JP1082. This print is part of Set B

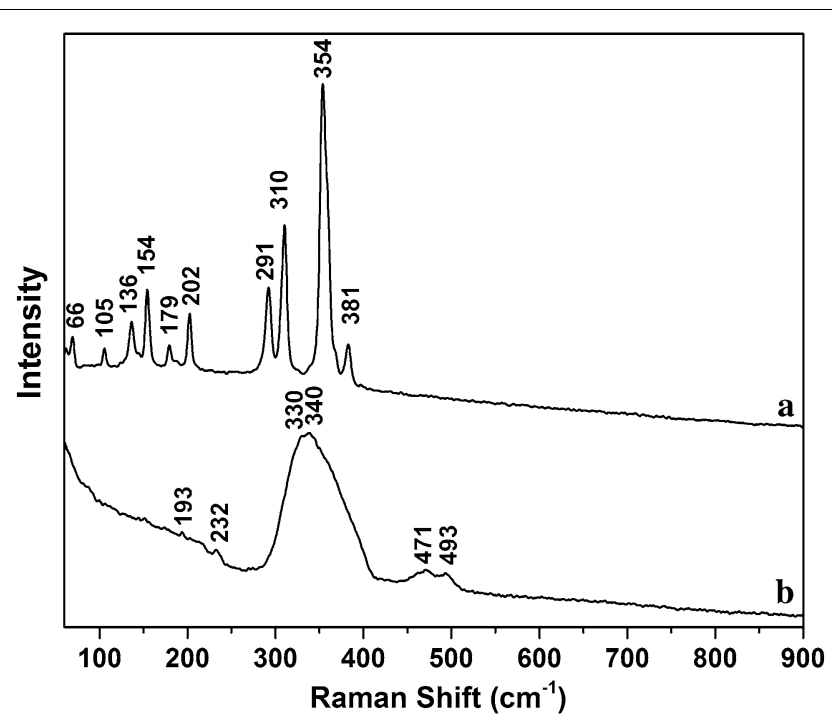

Fig. 2 Raman spectra obtained from yellow pigment particles on JP1082: acquired from yellow pigment particles in the (a) orange area and (b) yellow area. Peaks at $66,105,136,154,179,202,291,310,354$, and $381 \mathrm{~cm}^{-1}$ in a are typical of natural orpiment. Peaks at $193,232,493 \mathrm{~cm}^{-1}$ and the broad band at $330-340 \mathrm{~cm}^{-1}$ in $\mathrm{b}$ are typical of artificial arsenic sulfide. The peak at $471 \mathrm{~cm}^{-1}$ is from elemental sulfur 
$1 \mu \mathrm{m}$ diameter to $30 \mu \mathrm{m}$ diameter. The platelet-like features and heterogeneous particle size are characteristic of natural orpiment (Figs. 3 and 4). Figure 4 displays smaller orpiment particles: particle 3 is approximately $1 \mu \mathrm{m}$ in diameter and particle 1 is $6 \mu \mathrm{m}$. Semi-quantitative EDS yielded an arsenic composition of $60.14 \mathrm{wt} \%$ and a sulfur composition of $39.96 \mathrm{wt} \%$ for the particle in Fig. 3. The average arsenic and sulfur content for the particles in Fig. 4 are $58.3 \pm 5.1$ and $41.7 \pm 5.1 \mathrm{wt} \%$, respectively. The measured particle size and the relative arsenic and sulfur content strongly indicate natural orpiment. Trace amounts of copper were detected from the particles in Figs. 3 and 4, likely due to the co-existence of arsenic and copper in arsenic mines $[29,30]$. Trace antimony, which can co-occur in arsenic mines, was also detected in the larger orpiment particle displayed in Fig. 3 [31].

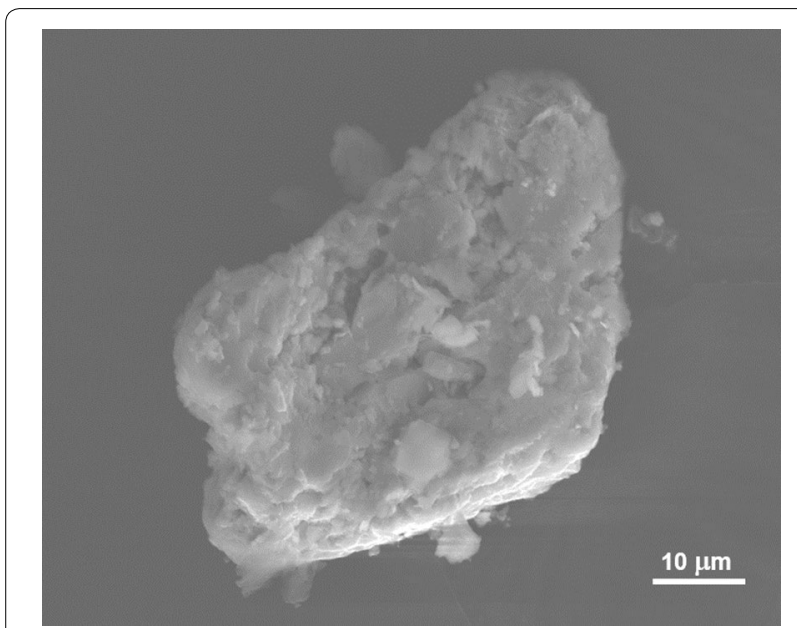

Fig. 3 BSE image of an isolated orpiment particle from JP2925: the platelet-like morphology is characteristic of natural orpiment

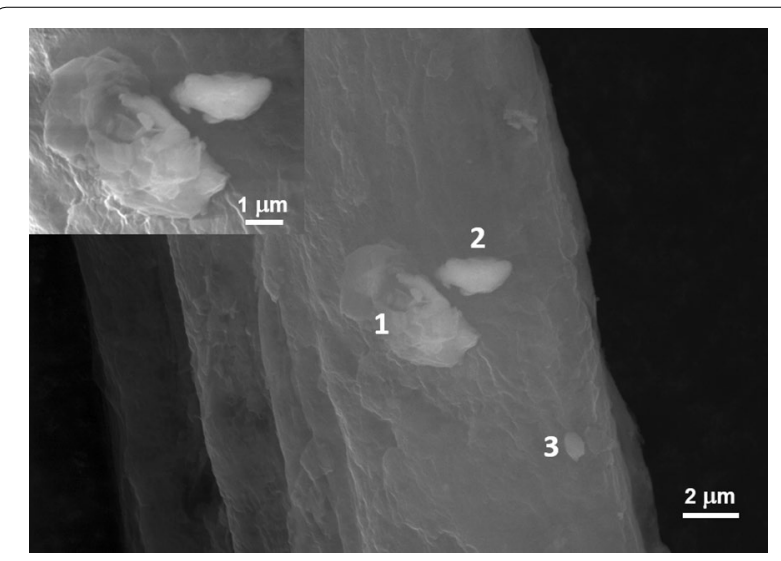

Fig. 4 BSE image of orpiment particles [1-3] on a paper fiber from JP2925. Inset: higher magnification BSE image of orpiment particles 1 and 2. The platelet-like features and heterogeneous particle size are characteristic of natural orpiment
Yellow pigment particles found on paper fibers sampled from JP1082 and JP1085 (both belonging to Set B) are of spheroidal shape and range from 1 to $3 \mu \mathrm{m}$ in diameter (Figs. 5 and 6). On average, the arsenic and sulfur-containing particles had an arsenic content of $47.5 \pm 4.0 \mathrm{wt} \%$ and a sulfur content of $52.6 \pm 4.0 \mathrm{wt} \%$. The measured arsenic and sulfur content, and in particular, the excess amount of sulfur is strongly indicative of artificial arsenic sulfide $[17,18]$. Trace amounts of copper were also detected in the particles shown, and no $\mathrm{As}_{2} \mathrm{O}_{3}$ was detected on the paper fibers.

To complete the analysis, we also characterized the blue and green areas encountered in each print examined. XRF and Raman analysis (data not shown) allowed us to identify Prussian blue and indigo, used consistently throughout Set A in admixture with orpiment for the greens and alone for the darker blue tones. By way of example, the Raman spectrum acquired from blue regions generally displays prominent peaks at 1574 (indigo) and $2151 \mathrm{~cm}^{-1}$ (Prussian blue). The lighter blue

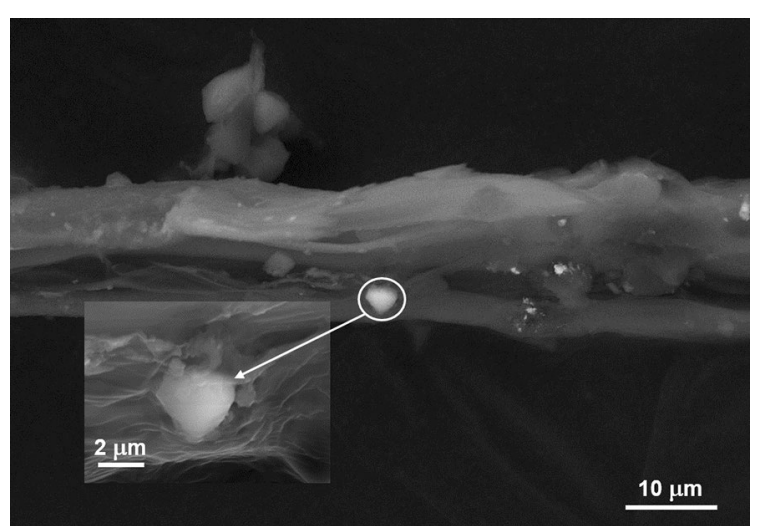

Fig. 5 BSE image of a pigment particle (circled, inset) on a paper fiber from a yellow area of JP1082. The small size, homogeneous size distribution and the chemical composition of the particles is typical of artificial arsenic sulfide

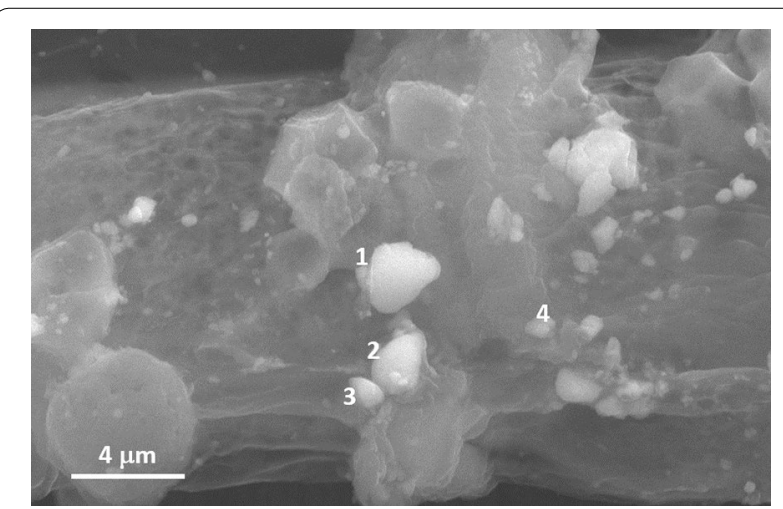

Fig. 6 BSE image of artificial arsenic sulfide particles (labeled 1-4) on a paper fiber from JP1085 
areas were found to contain only Prussian blue. Finally, the blue outlines of the prints in Set A contain both indigo and Prussian blue.

For prints in Set B, all blue areas, including the outlines were found to contain a mixture of Prussian blue, indigo, and ultramarine blue. For greens, the three blue pigments are found together with artificial arsenic sulfide.

\section{Discussion}

The prints analyzed in this study can be split into two subsets: those that use natural orpiment as a yellow pigment (Set A) and those that use artificial arsenic sulfide (Set B). The prints with brighter green and yellow tones in Set A used natural orpiment in the yellow and green areas of the print. The yellow pigment found in these prints exhibited the characteristic Raman spectrum of orpiment (Fig. 1), and SEM images showed flat platelike particles between 1 and $30 \mu \mathrm{m}$ in size, also typical of natural orpiment. In contrast, the prints with relatively duller yellow and green tones in Set B were found to use artificial arsenic sulfide, as indicated by the homogeneous 1-3 $\mu \mathrm{m}$ diameter spherical pigment particles, the broader Raman peaks, and the excess in sulfur detected by SEM-EDS. The Raman and SEM-EDS data of the artificial arsenic sulfide identified in the prints agrees well with previous reports of dry-process artificial orpiment $[1,2,8,18]$. A notable exception to the distinctive use of natural orpiment in Set A and artificial arsenic sulfide in Set B was print JP1082 (Set B). In this print, in addition to artificial arsenic sulfide in the yellow and green areas, we found natural orpiment, limited to the orange areas of the print and mixed with iron oxide red (as identified by XRF and Raman). Thus, natural orpiment was mixed with a red pigment with the intent of obtaining a bright orange tone. This finding implies that natural orpiment was available alongside the artificial sulfide at the time the prints in Set B were published.

Combining the technical results with information from period literary sources can assist in elucidating arsenic sulfide pigment origin and production methods. Despite the existence of artificial orpiment production in the West for hundreds of years, the earliest literary reference in English to artificial orpiment specifically produced in East Asia dates to 1831, in Samuel Gray's A Supplement to the Pharmacopœia and Treatise on Pharmacology, which states that natural orpiment is "found in mines, yellowish green, with brilliant gold-coloured spangles; used by painters" and its artificial counterpart was synthesized "from orpiment, by sublimation; from China, Japan and the Burman empire" [32]. Additional documentary evidence from this period states that in Japan, imported orpiment was prepared for use as a pigment by grinding, and artificial orpiment was produced by the dry process, as learned from the Dutch [14, 16]. The first detailed description of artificial orpiment specific to Japan dates to approximately 1846 , where Takamatsu describes the production of artificial orpiment by burning of arsenical stones with sulfur. Interestingly, Takamatsu performed chemical analysis of the artificially produced orpiment and demonstrated the presence of excess sulfur and no $\mathrm{As}_{2} \mathrm{O}_{3}$, in agreement with our experimental findings [18]. Takamatsu also cites the low cost of artificial orpiment compared to gamboge, making it an appealing colorant to use for the production of woodblock prints. Based on the literary descriptions cited above, it is likely that the natural orpiment used in the prints we studied was imported from China, and that the artificial orpiment used was produced by sublimation of mineral orpiment (with or without sulfur added). This finding is consistent with our experimental results. It is not possible however to distinguish between artificial orpiment imported from China or produced in Japan due to the chemical similarities of the two dry process products.

Assigning accurate chronology to woodblock prints such as the Waterfalls series is challenging due to the commercial nature of print production. Woodblocks could be passed between publishers, and hundreds to thousands of print copies could be produced in a single printing. Additionally, the Waterfalls series prints were known to be heavily copied in the nineteenth century from a newly carved set of blocks; it is believed that more copies exist in public collections than originals $[21,33,34]$. We attempt to use the identification of both yellow and blue pigments in order to corroborate the production date of the prints studied. Multiple sources state that the Waterfalls series prints were first issued in 1833, and widely published in 1834-1835 [33, 35, 36]. The prints that use artificial arsenic sulfide (Set B) also used blue pigments Prussian blue, indigo, and ultramarine. This is unlike the prints with natural orpiment (Set A), which were found to use only Prussian blue and indigo, and highly unusual. Natural ultramarine, or lapis lazuli, was not native to Japan and was extremely costly; it is therefore unlikely that natural ultramarine was used for commercial woodblock prints. Artificial ultramarine, first synthesized in 1828 (independently by Gmelin in Germany and Guimet in France), became commercially available in Europe on large scale only after 1830 [37]. Taken together with the tentative dating to the late Edo-early Meiji period for Set B, and with the co-occurrence of artificial arsenic sulfide pigment, so far only found in Meiji prints, the finding of artificial ultramarine in JP1081-JP1088, is in line with the findings of Fitzhugh [14], who in her survey of Edo period paintings at the Freer Gallery identified artificial ultramarine only 
in later Edo period paintings by Hiroshige (1797-1858) and Hiroshige II (1826-1869).

\section{Conclusions}

This study investigated the use of arsenic sulfide pigments in late Edo period Japanese woodblock prints with the goal of better understanding when artificial arsenic sulfide pigments were first produced and used in Japan. First, we used a multi-analytical approach to identify both natural orpiment and artificial arsenic sulfide in prints from the Waterfalls series by Katsushika Hokusai. We then examined historic sources to understand artificial arsenic sulfide pigments production in Asia during the nineteenth century. Based on our experimental findings and historic literary references, we propose that the orpiment used in the prints studied was sourced from China and the artificial arsenic sulfide was produced by the dry process method. The finding of natural orpiment in the prints belonging to the first edition printing and both artificial arsenic sulfide and ultramarine in the reproduction set aided in corroborating the production dates of the prints studied, where the colorants detected agreed well with a printing date of $1833-1835$ for set $\mathrm{A}$, and in the very late Edo period or early Meiji period in the case of Set B.

\section{Authors' contributions}

The research project idea was generated by $\mathrm{ML}$, who also selected the prints to be studied. XRF, Raman and SEM-EDS analyses were performed by SZ and $\mathrm{YT}$. The manuscript was prepared by SZ and ML. All authors read and approved the final manuscript.

\section{Author details}

${ }^{1}$ Department of Scientific Research, The Metropolitan Museum of Art, New York, NY 10028, USA. ${ }^{2}$ Present Address: Department of Biomedical Engineering, George Washington University, Washington, DC 20052, USA.

\section{Acknowledgements}

We thank John T. Carpenter, Mary Griggs Burke Curator of Japanese Art at The Metropolitan Museum of Art for his support and advice. S.Z. gratefully acknowledges the Sherman Fairchild Foundation Postdoctoral fellowship for financial support.

\section{Competing interests}

The authors declare that they have no competing interests.

\section{Availability of data and materials}

All data is available upon request.

\section{Ethics approval and consent to participate}

Not applicable.

\section{Funding}

Not applicable.

\section{Publisher's Note}

Springer Nature remains neutral with regard to jurisdictional claims in published maps and institutional affiliations.

Received: 14 February 2018 Accepted: 2 May 2018

Published online: 22 May 2018

\section{References}

1. FitzHugh EW. Orpiment and Realgar. In: FitzHugh EW, editor. Artists' pigments. A handbook of their history and characteristics, vol. 3. New York: Oxford University Press and National Gallery of Art; 1997.

2. Wallert A. Orpiment and realgar. Maltechnik-Restauro. 1984;4:45-57.

3. Dossie R. The handmaid to the arts. London: Nourse; 1758.

4. Cennino C. II libro dell'arte della pittura: il manoscritto della Bibliotheca Nazionale Centrale di Firenze, con integrazioni dal codice riccardiano. In: Torresi AP, editor. Ferrara: Liberty House; 2004.

5. Merrifield MP. Original treatises dating from the XIIth to XVIIIth centuries on the arts of paintings in oil, miniature, mosaic and glass. Originally published John Murray, London; 1849. New York: Dover Publications; 1999.

6. Grundmann G, Richter M. Types of dry-process artificial arsenic sulphide pigments in cultural heritage. In: Fatto d'Archimia Conference-Los Pigmentos artificiales en las técnicas pictóricas; Madrid, Spain. 2012. p. 119-44.

7. Rotter C. Auripigment, genauere Betrachtung eines historischen Pigments. Restauro. 2003:109(6):408-13.

8. Vermeulen M, Sanyova J, Janssens K. Identification of artificial orpiment in the interior decorations of the Japanese tower in Laeken, Brussels, Belgium. Heritage Sci. 2015;3(1):9.

9. Harley RD. Artists' pigments C. 1600-1835. 2nd ed. London: Archetype Publications; 2001.

10. Schafer EH. Orpiment and realgar in Chinese technology and tradition. J Am Orient Soc. 1955;75(2):73-89.

11. Silbergeld J, McNair A. Chinese painting colors: studies of their preparation and application in traditional and modern times. Hong Kong: Hong Kong University Press and University of Washington Press; 1988.

12. Burmester A. Technical studies of Chinese lacquer. In: Bromelle BS, Smith P, editors. Urushi: proceedings of the 1985 Urushi Study Group. Tokyo: Getty Publications; 1988. p. 163-87.

13. FitzHugh EW. A pigment census of ukiyo-e paintings in the Freer Gallery of Art. Ars Orientalis. 1979:11:27-38.

14. FitzHugh EW. A database of pigments on Japanese ukiyo-e paintings in the Freer Gallery of Art. Washington DC: Pigments in Later Japanese Paintings; 2003.

15. Yamato A. Koku ukiyo-e hanga ni shiyo sareta shikizai no hensen ni kansuru kenkyu (Studies on changes in the colorants used in later ukiyo-e prints). MA Thesis. Japan: Tohoku University of Art and Design. 2013.

16. Kitano N, Koezuka T. Fundamental research on sekio (orpiment) contained in excavated Urushi objects of the Edo period (I) [original title and text in Japanese]. Bunkazai Hozon Shufuku Gakkai shi. 2000:44:70-9.

17. Luo Y, Basso E, Smith HD, Leona M. Synthetic arsenic sulfides in Japanese prints of the Meiji period. Heritage Sci. 2016;4:17.

18. Takamatsu T. On Japanese pigments. Tokyo: Department of Science in Tokio Daigaku; 1878.

19. Meech-Prekarik J. Early collectors of Japanese prints and the Metropolitan Museum of Art. Metrop Mus J. 1982;17:93-118.

20. Priest A. Japanese prints from the Henry L. Phillips Collection. New York: The Metropolitan Museum of Art; 1947.

21. Keyes R, Morse P. Hokusai's waterfalls and a set of copies. Orient Art. 1972;18(2):141-7.

22. Bell IM, Clark RJH, Gibbs PJ. Raman spectroscopic library of natural and synthetic pigments (pre- 1850 AD). Spectrochim Acta A Mol Biomol Spectrosc. 1997:53:2159-79.

23. Burgio L, Clark RJH. Library of FT-Raman spectra of pigments, minerals, pigment media and varnishes, and supplement to existing library of Raman spectra of pigments with visible excitation. Spectrochim Acta A Mol Biomol Spectrosc. 2001;57(7):1491-521.

24. Georgiev DG, Boolchand P, Jackson KA. Intrinsic nanoscale phase separation of bulk $\mathrm{As}_{2} \mathrm{~S}_{3}$ glass. Philos Mag. 2003;83(25):2941-53.

25. Grundmann G, Richter M. Current research on artificial arsenic sulphide pigments in artworks: a short review. CHIMIA Int J Chem. 2008;62(11):903-7.

26. Holomb RM, Mitsa VM. Simulation of Raman spectra of $A s_{x} S_{100-x}$ glasses by the results of ab initio calculations of $\mathrm{As}_{n} \mathrm{~S}_{\mathrm{m}}$ clusters vibrations. J Optoelectron Adv Mater. 2004;6(4):1177-84.

27. Ward AT. Raman spectroscopy of sulfur, sulfur-selenium, and sulfur-arsenic mixtures. J Phys Chem. 1968;72(12):4133-9.

28. Golovchak R, Shpotyuk O, McCloy JS, Riley BJ, Windisch CF, Sundaram SK, et al. Structural model of homogeneous As-S glasses derived 
from Raman spectroscopy and high-resolution XPS. Philos Mag. 2010;90(34):4489-501.

29. Geerts AJC. Useful minerals and metallurgy of the Japanese. Trans Asiat Soc Jpn. 1877:3:25-37.

30. Plunkett FR. Report on the mines of Japan. Jpn Mail. 1876;7(1):74-81.

31. Xianxiao X. Classification, minerogenic models and prospecting of realgar/orpiment deposits in China. Acta Geol Sin. 2000;74(3):618-22.

32. Gray SF. A supplement to the pharmacopœia and treatise on pharmacology in general. 4th ed. London:W. Clowes; 1831.
33. Lane R. Hokusai: life and work. London: Barrie and Jenkins; 1989.

34. Edmunds WH. The Identification of Japanese Colour Prints. The Burlington Magazine. 1922;226(40):31-6.

35. Calza GC. Hokusai. London: Phaidon; 2003.

36. Clark T. Hokusai: beyond the great wave. London: Thames \& Hudson; 2017.

37. Mertens J. The history of artificial ultramarine (1787-1844): science, industry and secrecy. Ambix. 2004;51(3):219-44.

\section{Submit your manuscript to a SpringerOpen ${ }^{\circ}$ journal and benefit from:}

- Convenient online submission

- Rigorous peer review

- Open access: articles freely available online

- High visibility within the field

Retaining the copyright to your article

Submit your next manuscript at $\boldsymbol{\nabla}$ springeropen.com 